\title{
Dynamic Google SketchUp Software and Conventional Teaching Strategy of Students' Conceptual Knowledge and Procedural Knowledge in Learning Geometry
}

\author{
Tan Tong Hock \\ IPG Kampus Pendidikan Teknik, Kuala Lumpur, Malaysia
}

\begin{abstract}
Ahmad Fauzi Mohd Ayub (Corresponding author)
Faculty of Educational Studies, Universiti Putra Malaysia, 43400 UPM Serdang, Selangor, Malaysia

Institute for Mathematical Research, Universiti Putra Malaysia, 43400 UPM Serdang, Selangor, Malaysia
\end{abstract}

Aida Suraya Md Yunus

Faculty of Educational Studies, Universiti Putra Malaysia, 43400 UPM Serdang, Selangor, Malaysia

Institute for Mathematical Research, Universiti Putra Malaysia, 43400 UPM Serdang, Selangor, Malaysia

Nur Raidah Mohd Salim

Institue for Mathematical Research, Universiti Putra Malaysia, 43400 UPM Serdang, Selangor, Malaysia

Received: Oct. 8, $2021 \quad$ Accepted: Nov. 15, $2021 \quad$ Online published: Nov. 25, 2021

doi:10.5296/ijhrs.v11i4S.19253 URL: https://doi.org/10.5296/ijhrs.v11i4S.19253

\begin{abstract}
The purpose of this study is to identify the effect of using dynamic software Google SketchUp (GSU), without software on van Hiele's theory and conventional teaching strategy of students' conceptual and procedural knowledge in learning geometry among primary
\end{abstract}


school students. The study was conducted using pre and post-test true experimental methods. This true experimental research involved 96 students from Year Five primary schools in Malaysia. The selection of site or school take into account as convenience and voluntary participation. The study's findings showed significant differences in student's conceptual knowledge and procedural knowledge based on the different types of the strategy group. The post hoc test indicated that using software showed better conceptual and procedural knowledge when compared to without using software on van Hiele's theory and conventional teaching strategy.

Keywords: conceptual knowledge, procedural knowledge, Google SketchUp (GSU)

\section{Introduction}

\subsection{Introduce the Problem}

Many mathematics educators have ignored the importance of mathematics understanding, which is the foundation of program ability. According to studies done by Mitchelmore (2002) and Sulistyowati et al. (2017) on lower secondary students (Grade 7 and 8), problem solving skills, geometry concepts, and geometry reasoning are all affected by learning difficulties in geometry. A student who does not have a solid grounding in geometry in lower secondary school may face this problem in upper secondary school. Some students might struggle with more complex geometry concepts such as transformations and trigonometry. According to Abdul Halim and Mohini (2008), there is too much emphasis on naming and identifying geometric symbols in the current syllabus of geometry, which neglects the depth of geometry understanding. Solving geometry problems as well as exploring space, analyse and synthesizing were not emphasized. Therefore, the technique of learning geometric concepts should be implemented effectively. Instead of using traditional methods that focus more on memorizing geometric concepts, it is better to change students' geometric learning experience more meaningfully.

\subsection{Importance of the Problem}

The utilization of technological advancement available nowadays has allowed both teachers and students to have better and more effective ways of learning geometry. According to Goker, Ozaydin, and Tekedere (2016), with the proper colours and interfaces, video-assisted topic explanations, questions to reinforce the subjects, and entertainment games with audio-visual feedback, educational software could contribute uniquely to children's learning. The teacher can effectively address the challenge of organizing mathematics instruction to attract and develop the abilities of the most significant possible number of students (Abdul Halim 2013; NCTM, 2000). Furthermore, through using the technological tools, students can develop geometrical knowledge in terms of visual, concept, and procedures in understanding knowledge acquisition in mathematics education (Hutkemri \& Effandi, 2012). In addition, Usiskin (1982) has described concepts in geometry, such as the study of our physical world, by representing them using a mathematical system.

According to Hiebert (2013), students' conceptual knowledge and procedural knowledge vary throughout their learning school years. Students tend to tie in procedural knowledge rather 
than conceptual knowledge since their early childhood learning to develop their understanding of procedural knowledge is more likely to be during their preschool years. Students will not understand the calculations and mathematical knowledge if they have not mastered both. Students may only answer if the concepts and procedures are unrelated but do not understand what they are doing. These things are caused by a lack of conceptual and procedural knowledge. Yurniwati and Soleh (2019) stated that conceptual knowledge (CK), which facilitates understanding of abstract concepts, and procedural knowledge (PK), which assists in solving concrete problems. They are fundamentally connected to the way and in what order they are taught. Thus, when teachers transmit mathematical content, they must incorporate both types of knowledge.

Noraini's (2006) study in geometry instruction, much of the learning experiences rest on the teacher. In the classroom, students are introduced to facts about Euclidean geometry and instructed to apply deductive reasoning to the format of multiple shapes. Students are only given little opportunities to discover and conceptualize geometry on their own. It is often pictured that students are doing geometry lessons by copying diagrams from the board and then repeating calculations to determine angles, lengths, and areas of figures. However, conceptual and procedural knowledge are the two types of knowledge considered different, but they are closely related. Whether procedural knowledge is to be mastered before conceptual knowledge is not an issue because, in learning, the two types of knowledge can grow together. Therefore, linking conceptual and procedural knowledge is essential in the learning process, as it helps students develop a deeper understanding of concepts and strengthens the procedures used. Unfortunately, recently most schools are over-concerned with developing procedural knowledge rather than conceptual knowledge. Further more, there have been a lot of researches conducted on teachers' conceptual knowledge and secondary school students in several mathematical topics, however there is still a lack of research in investigating primary students conceptual knowledge and procedural knowledge in learning geometry (Abdullah, 2019; Mazlini et al., 2021)

\subsection{Objective of the Study}

This study aimed to investigate the influence of instructional learning geometry using van Hiele's phases of learning (VHG-PL) and van Hiele's levels of thinking using dynamic Google SketchUp (VHG-GSU) compare to conventional teaching (CI) on students' performance in conceptual and procedural knowledge. Therefore the research questions are as follows

1. The impact of Google SketchUp Software and without software on conceptual knowledge before and after the intervention of three different groups.

2. The impact of Google SketchUp Software and without software on conceptual knowledge on the post-test between students of three different groups.

3. The impact of Google SketchUp Software and without software on procedural knowledge before and after the intervention of three different groups. 


\section{MlMacrothink}

International Journal of Human Resource Studies

ISSN 2162-3058

2021, Vol. 11, No. 4S

4. The impact of Google SketchUp Software and without software on procedural knowledge on the post-test between students of three different groups.

\subsection{Hypothesis of the Study}

$\mathrm{H}_{01}$ There is no significant difference in the overall mean scores in conceptual knowledge before and after after the intervention of three different groups.

$\mathrm{H}_{02}$ There is no significant difference in the overall mean scores in conceptual knowledge between students who undergo different strategies in learning geometry.

$\mathrm{H}_{03}$ There is no significant difference in the overall mean scores in procedural knowledge before and after after the intervention of three different groups

$\mathrm{H}_{04}$ There is no significant difference in the overall mean scores in procedural knowledge between students who undergo different strategies in learning geometry.

\subsection{Literature Review}

Star (2002) noted that "the term conceptual knowledge has come to encompass not only what is known (knowledge of concepts) but also one way that concepts can be known (e.g., deeply and with rich connections)" (p.408). According to Hiebert (2013):

Conceptual knowledge is characterized most clearly as the knowledge that is rich in relationships. It can be thought of as an interconnected web of knowledge, a network in which the linking relationships are as prominent as discrete information. Relationships pervade the individual facts and propositions so that all pieces of information are linked to some network (pp. 3-4).

Conceptual knowledge also can be assumed in some form of relational representation, through interlinked connections (Stella et al. 2017; Vitevich \& Castro 2015). Abstract conceptual knowledge can be largely verbalized and flexibly transformed through inferences and reflections, If students with good inhibitory control use alternative conceptual strategies instead of computation to solve problems, they will have a better chance of solving those problems than children with poor inhibitory control (Robinson \& Dube, 2013) Nowadays, with the proliferation of information and communication technology (ICT), there is a lot of interest in using ICT in education. In the teaching and learning of geometry, there is quite a number of software to choose from. Google SketchUp (GSU) is an open-source software technology that can represent mathematics to make it easier for students to relate the real world to the world of mathematics. Google SketchUp is easy and intuitive to understand for the students to use on their computers. The presented GSU models were so attractive that they could motivate the students to understand spatial problems by creating corresponding virtual models. Virtual models should help students realize that the spatial thinking required for solving all drawings comes from the drawing itself (Leopold, 2008).

The picture produced in Google SketchUp is a mathematical object that can be represented by using the software. To reflect the real world, the software can explain mathematical concepts to relate the mathematical things to the real world. For example, in solving a math question, 
students need to understand the requirements of a question before planning strategy solutions. After that, they will correlate the information with what to look for, and then they will solve the question. Of course, they should get the correct information to start with. In this study, the learners have to understand the concept and properties of triangles, squares and rectangles, cubes, and cuboids before reaching the levels of geometry thinking required.

On the other hand, as Hiebert (2013) defines, formal language and symbol representation are crucial parts of procedural knowledge in mathematics. They represent the algorithms and rules to complete the mathematical tasks. It means that procedural knowledge includes structural knowledge and algorithmic knowledge. The former is knowledge related to the meaning and symbols. It implies an awareness of superficial features but not knowledge of meaning.Knowledge of defined algorithmic symbols involves knowledge of mathematical symbols and rules of use. It does not necessarily involve general purposes. Defined procedural knowledge refers to mathematical equations or a form of writing and not on mathematical content knowledge. Hiebert (2013) also stated that the ability of students to solve the problem with the correct steps of calculation using a good strategy or algorithm represents a solid and powerful procedure. It is an important feature of structured and hierarchical procedures. Step by step or part of a procedural network can be characterized as an advantage of creating a solid procedure in all aspects of procedure learning in mathematics.

Based on the definition above on procedure, in this study, procedural knowledge is the ability of students to use a specific procedure to solve the problem by using symbols through a step-by-step layout and using the formula in the calculation process such as to find the formula of the perimeter; area and volume to solve problems include conventional teaching strategies, dynamic software and without software strategies. The procedural knowledge representation relies on van Hiele's levels of geometry thinking.

\section{Method}

This study used a true-experimental design with a pre-test and post-test equivalent and a control group to study the impact on the actual situation.

\subsection{Participant (Subject) Characteristics}

The participants consist of 96 Year Five students, and distributed randomly in conventional group (CI), dynamic software group (VHG-GSU) and without software group (VHG-PL). It is theorized that the strongest comparisons come from true experimental designs in which subjects (students, teachers, classrooms, schools, etc.) are randomly assigned to program and comparison groups (Fraenkel, Wallen \& Hyun, 2011). Each group have 32 participants. Wu's Geometry Test was conducted to balance the number of students' gender in each group in this study.. Furthermore, the participants carry out a similar daily routine in school.

\subsection{Sampling Procedures}

The participants would go through the random selection according to the number of different levels of geometric thinking. After regrouping, the participants would be randomly selected 
into the conventional group (CI), dynamic software group (VHG-GSU) and without software group (VHG-PL). The first treatment group used a module developed with van Hiele's theory using dynamic Google SketchUp (VHG-GSU) software as a medium of implementation and the second treatment group used van Hiele's Phases Learning Module (VHG-PL). Additionally, the students in the control group (CI) were exposed to the same topics in a conventional way. They were given a conceptual knowledge and procedural knowledge pre-test in the first week before learning sessions were conducted.

\subsubsection{Measures and Instruments}

Instruments used to measure conceptual knowledge and procedural knowledge for the topics geometry each contained ten questions. Questions testing the knowledge of conceptual and procedural knowledge are aligned with learning objectives. In addition, the test was developed by the researcher with the assistance of his supervisor and an experienced mathematics teacher. Questions were adapted from a study conducted by Hutkemri (2012).

\section{Results}

\subsection{Comparing Conceptual Knowledge Pre and Post-Test for All Groups}

This analysis will describe the mean score for pre-test and post-test for all groups. All groups showed a higher mean post-test score than the mean pre-test score in Table 1 for each group.

Table 1. Mean and Standard Deviation of Conceptual Knowledge

\begin{tabular}{cccccc}
\hline & N & $\begin{array}{c}\text { Pre-test } \\
\text { mean }\end{array}$ & SD & $\begin{array}{c}\text { Post-test } \\
\text { Mean }\end{array}$ & SD \\
\hline CI & 32 & 8.39 & 6.04 & 27.60 & 13.25 \\
VHG-PL & 32 & 8.75 & 3.05 & 30.86 & 11.28 \\
VHG-GSU & 32 & 8.67 & 4.71 & 47.27 & 13.67 \\
\hline
\end{tabular}

The following analysis will analyse the difference in the mean score of Pre-test and Post-test for all groups studied. Therefore, paired sample t-test was used to explore the differences in the scores of Pre-tests and Post-test. Table 2 shows the analysis for all their groups. There was a statistically significant difference in the mean score conceptual knowledge for CI group between Pre-test score $(\mathrm{M}=8.39, \mathrm{SD}=6.04)$ and Post-test score $(\mathrm{M}=27.60, \mathrm{SD}=13.25)$; [ $\mathrm{t}$ (30) $=-8.59, \mathrm{p}=.0001<.005]$. Eta squared $(\eta 2)$ was 0.71 shown the effect of the group. The actual difference in mean scores among Pre and Post-test was large (Cohen, 1988). For the VHG-PL group, there was a statistically significant difference in the mean score of conceptual knowledge between Pre-test $(\mathrm{M}=8.75, \mathrm{SD}=3.05)$ and Post-test $(\mathrm{M}=30.86$, $\mathrm{SD}=11.28),[\mathrm{t}(31)=-11.49, \mathrm{p}=.0001<.005]$. Eta squared $(\eta 2)$ was 0.81 (large effect). Lastly, for VHG-GSU group, Result of paired sample t-test shows statistically significant difference in the mean score between Pre-test $(M=8.67, S D=4.71)$ and Post-test $(M=47.27$, 
$\mathrm{SD}=13.67),[\mathrm{t}(31)=-16.94, \mathrm{p}=.0001<.005]$. The large effect of eta squared $(\eta 2)$ was 0.90 . This analysis indicated that students in the groups significantly score better post-test results than the pre-test score.

Table 2. Paired Samples t-Test of Conceptual Knowledge of all groups

\begin{tabular}{|c|c|c|c|c|c|c|}
\hline Groups & Types of tests & Mean & SD & $\mathrm{t}$ & $\mathrm{df}$ & Sig \\
\hline \multirow{2}{*}{$\mathrm{CI}$} & Pretest & 8.39 & 6.04 & \multirow{2}{*}{-8.586} & \multirow{2}{*}{30} & \multirow{2}{*}{.000} \\
\hline & Post-test & 27.60 & 13.25 & & & \\
\hline \multirow{2}{*}{ VHG-PL } & Pretest & 8.75 & 3.05 & \multirow{2}{*}{-11.49} & \multirow{2}{*}{31} & \multirow{2}{*}{.000} \\
\hline & Post-test & 30.86 & 11.28 & & & \\
\hline \multirow{2}{*}{ VHG-GSU } & Pretest & 8.67 & 4.71 & \multirow{2}{*}{-16.94} & \multirow{2}{*}{31} & \multirow{2}{*}{.000} \\
\hline & Post-test & 47.27 & 13.67 & & & \\
\hline
\end{tabular}

3.2 Comparing Conceptual Knowledge for All Groups Between All Groups

Comparing all groups of students undergoing different geometry learning strategies (VHG-GSU, VHG-PL, and CI) and controlling for their scores during pre-testing, the following analysis analyses the mean score of conceptual knowledge. For this purpose, analysis ANCOVA was used. After adjustment for Pre-test of conceptual knowledge, the Post-test of conceptual knowledge showed significant differences in each group, $[F(2,91)=$ 23.54, $p=.0001<.005]$, partial $\left(\eta^{2}\right)$ equal .341 (Table 3 ). The results found that there were significant differences in overall conceptual knowledge among students who received different geometry teaching strategies (VHG-GSU, VHG-PL, and CI) when controlling their performance before the exam. Eta squared $\left(\eta^{2}=.341\right)$ shows there is a large effect between three groups intervention.

Table 3: Tests of Between-Subjects Effects of Conceptual Knowledge Test

\begin{tabular}{ccccccc}
\hline Source & $\begin{array}{c}\text { Type III Sum of } \\
\text { Squares }\end{array}$ & df & $\begin{array}{c}\text { Mean } \\
\text { Square }\end{array}$ & F & Sig. & $\begin{array}{c}\text { Partial Eta } \\
\text { Squared }\end{array}$ \\
\hline Group & 6958.285 & 2 & 3479.143 & 23.544 & .000 & .341 \\
\hline
\end{tabular}

A post hoc test, using Bonferroni adjustment, was employed to analyse further which group differed from the other groups (refer to Table 4). VHG-GSU group $(M=47.27, S D=13.67)$ was statistically significantly different when compared to VHG-PL group $(M=30.86, S D=$ 11.28) and CI group $(M=27.60, S D=13.25)$ (refer Table 4). However, there was no significant difference between the VHG-PL and CI groups. These results indicate that students in the VHG-GSU group have better conceptual knowledge than other groups. 
Table 4. Pairwise Comparisons of Conceptual Knowledge Post-test

\begin{tabular}{|c|c|c|}
\hline \multirow{2}{*}{ (I) Groups } & J) Groups & Sig. $^{\text {b }}$ \\
\hline \multirow{2}{*}{ CI (M=27.60) } & VHG-PL (M=30.86) & 1.000 \\
\cline { 2 - 3 } & VHG-GSU (M=47.27) & .000 \\
\hline \multirow{2}{*}{ VHG-PL (M=30.86) } & CI (M=27.60) & 1.000 \\
\cline { 2 - 3 } & VHG-GSU (M=47.27) & .000 \\
\hline \multirow{2}{*}{ VHG-GSU (M=47.27) } & CI (M=27.60) & .000 \\
\cline { 2 - 3 } & VHG-PL (M=30.86) & .000 \\
\hline
\end{tabular}

In conclusion, there were significant differences in the Pre-test and Post-test of conceptual knowledge in the three different groups (VHG-GSU, VHG-PL, and CI). Results from eta squared show a significant actual effect between Pre-test and Post-test of conceptual knowledge. The analysis of covariance showed that, after controlling for the pre-test, there was a significant difference in the average overall concept understanding during the post-test period among students who used different strategies (VHG-GSU, VHG-PL, and CI) in geometry learning. Among the learning strategies, dynamic Google SketchUp software strategy was the better instruction in promoting conceptual knowledge. The result once again showed the importance of technology education.

\subsection{Comparing Procedural Knowledge Pre and Post-Test for All Groups}

For procedural knowledge, the mean and standard deviation scores for all groups as shown in Table 5. The result showed that students in all groups scored higher scores in the post-test compared to the pre-test.

Table 5. Mean and Standard Deviation of Procedural Knowledge

\begin{tabular}{|c|c|c|c|c|c|}
\hline & $\mathrm{N}$ & Pre-test mean & SD & Post-test Mean & SD \\
\hline CI & 32 & 23.71 & 8.55 & 37.50 & 16.22 \\
\hline VHG-PL & 32 & 21.75 & 6.56 & 43.53 & 13.92 \\
\hline VHG-GSU & 32 & 30.64 & 15.30 & 60.75 & 14.73 \\
\hline
\end{tabular}

Table 6 shows paired sample t-test, which explored the differences in the Pre-test and Post-test scores of procedural knowledges. The mean overall difference between pre-test $(\mathrm{M}=23.71, \mathrm{SD}=8.55)$ and post-test $(\mathrm{M}=37.50, \mathrm{SD}=16.22)$ of procedural knowledge is statistically significant, [t $(30)=-6.96, p=.0001<.005]$. Eta squared $(\eta 2)$ was 0.62 (large effect size). This showed that there were significant differences in the post-test of procedural knowledge. Similarly, Results shows statistically significant difference in the mean overall of 
procedural knowledge Pre-test $(\mathrm{M}=21.75, \mathrm{SD}=6.56)$ and Post-test $(\mathrm{M}=43.53, \mathrm{SD}=13.92),[t$ $(31)=-9.36, p=.0001<.005]$. This suggested a significant difference after the Post-test and a large effect of eta squared $\left(\eta^{2}=0.74\right)$ between the Pre-test and Post-test. In this VHG-GSU group, the paired sample t-test showed that the mean overall difference between the pre-test $(\mathrm{M}=30.64, \mathrm{SD}=15.30)$ and post-test $(\mathrm{M}=60.75, \mathrm{SD}=14.73)$ of procedural knowledge was statistically significant, $[t(31)=-15.39, p=.0001<.005]$. The large eta squared $\left(\eta^{2}\right) 0.88$, This suggested that there is a significant difference in Procedural Knowledge Post-test compared to Pre-test.

Table 6. Paired Samples t-Test of Procedural Knowledge of all groups

\begin{tabular}{ccccccc}
\hline Groups & Types of test & Mean & SD & $\mathrm{t}$ & $\mathrm{df}$ & $\mathrm{Sig}$ \\
\hline \multirow{2}{*}{ CI } & Pretest & 23.71 & 8.55 & & & \\
& Post-test & 37.50 & 16.22 & -6.958 & 30 & .000 \\
\multirow{2}{*}{ VHG-PL } & Pretest & 8.75 & 3.05 & & & \\
& Post-test & 30.86 & 11.28 & -9.36 & 31 & .000 \\
VHG-GSU & Pretest & 8.67 & 4.71 & & & \\
& Post-test & 47.27 & 13.67 & & & \\
& & & & & & \\
& &
\end{tabular}

ANCOVA again was used to evaluate the mean overall procedural knowledge after test performance between students who undergo different strategies in learning geometry (VHG-GSU, VHG-PL, and CI) after adjusting for their Pre-test scores. There was a statistically significant difference in the Post-test of procedural knowledge after adjustment for the Pre-test of procedural knowledge between the three different groups, $[\mathrm{F}(2,91)=15.81$, $p<.005]$, partial $(\eta 2)$ equal .258 as shown in Table 9 . The eta squared suggested a large effect (Cohen, 1988) and significant difference in the mean overall of Procedural Knowledge among three different strategies group.

Table 7. Tests of Between-Subjects Effects of Procedural Knowledge Test

\begin{tabular}{ccccccc}
\hline Source & $\begin{array}{c}\text { Type III Sum } \\
\text { of Squares }\end{array}$ & df & $\begin{array}{c}\text { Mean } \\
\text { Square }\end{array}$ & F & Sig. & $\begin{array}{c}\text { Partial Eta } \\
\text { Squared }\end{array}$ \\
\hline Group & 4386.475 & 2 & 2193.238 & 15.813 & .000 & .258 \\
\hline
\end{tabular}

In the Post hoc test, Bonferroni adjustment was employed to analyse the performance of each group. VHG-GSU group $(M=60.75, S D=14.73)$ has statistically significantly difference when compared to VHG-PL group $(M=43.53, S D=13.92)$ and CI group $(M=37.50, S D=$ $16.22)$. Interestingly, VHG-PL group $(M=43.53, S D=13.92)$ was also significantly different when compared to CI group $(M=37.50, S D=16.22)$. In comparison to other groups, students in the VHG-GSU group showed better procedural knowledge. VHG-PL group has better performance than the conventional group as well. 
Table 8. Pairwise Comparisons of Procedural Knowledge Post-test

\begin{tabular}{llc}
\hline \multicolumn{1}{c}{ (I) Groups } & \multicolumn{1}{c}{$(\mathbf{J})$ Groups } & Sig. $^{\text {b }}$ \\
\hline CI $(\mathrm{M}=37.50)$ & VHG-PL $(\mathrm{M}=43.53)$ & .033 \\
& VHG-GSU $(\mathrm{M}=60.75)$ & .000 \\
\hline VHG-PL (M=43.53) & CI $(\mathrm{M}=37.50)$ & .033 \\
& VHG-GSU $(\mathrm{M}=60.75)$ & .008 \\
\hline VHG-GSU (M=60.75) & CI $(\mathrm{M}=37.50)$ & .000 \\
& VHG-PL $(\mathrm{M}=43.53)$ & .008 \\
\hline
\end{tabular}

Therefore, analysis of Procedural knowledge of Pre-test and Post-test, there were significant post-test differences compared to the pre-test in each group. VHG-GSU group $\left(\eta^{2}=0.88\right)$ showed about $88 \%$ larger effect after intervention when compared to VHG-PL group $\left(\eta^{2}=\right.$ $0.74)$ and CI group $\left(\eta^{2}=0.62\right)$. Finally, covariance analysis showed a significant difference in the mean overall procedural knowledge after test performance among three learning strategies group (VHG-GSU, VHG-PL, and CI) after test performance controlling for their scores at Pre-test. Results show that the VHG-GSU strategy has a better effect on Procedural Knowledge, followed by the VHG-PL strategy and, finally conventional teaching method.

In conclusion, dynamic Google SketchUp software strategy improved instruction in promoting procedural knowledge among the learning strategies. However, without software strategy using van Hiele learning phases was also better in assisting the learners in learning procedural algorithms. These showed the two developed modules could help learners in geometry learning. Results also show that technology education is the way to assist learner's progress in procedural algorithms.

\section{Discussion}

Analysis of t-test and ANCOVA showed significant differences in conceptual knowledge and procedural knowledge on topics geometry among the three different groups of students in this study. The research showed that the VHG-GSU group had achieved higher conceptual knowledge and procedural knowledge, followed by the VHG-PL group and the CI control group. This indicates that the teaching and learning modules (VHG-GSU module and VHG-PL module) can improve conceptual understanding and procedural algorithms in learning geometry. The study shows that successful teaching modules can strengthen the students' conceptual understanding and procedural process. VHG-GSU module showed higher performance if compared with VHG-PL module and conventional teaching. This can be due to the use of "Google SketchUp" software. Students can directly view the sample figures in three dimensions angles and better understand the concept and calculation of perimeter, area, and volume. This finding is consistent with that of Hutkemri (2012), who stated that using the software could further strengthen and enhance students' conceptual knowledge and procedural knowledge.

VHG-GSU group who can use GSU software as a representation of mathematics has the advantage as the tool makes it easier for students to relate the authentic world to mathematics. The picture produced in Google SketchUp (GSU) is a representation of a mathematical object. 
To realize the real world, the software can explain mathematical concepts and relate mathematical objects in the real world. Hence, they will correlate the information with what to look for, and then they will solve the questions. Conceptual knowledge in mathematics is essential in the learning process. Methods of teaching concepts in modules developed for topic geometry prioritize concepts that linked students' experiences both in and outside the classroom. Teachers also know that knowledge is something that is not transferable from anyone.

On the contrary, the students can only build knowledge through interaction with the learning environment (Piaget, 1978; Vygotsky, 1978). Using the VHG-GSU module learning strategy and VHG-PL module learning strategy, students can explore the topic being studied compared to the conventional teaching method. In addition, students can solve the given problem correctly and provide clarification on questions due to better procedural algorithms. Leopold (2008) established that GSU can guide person actively learning to establish their angels and figures used in geometry idea through activities include examine and determine shapes. This method exist helpful for the development of explanatory and examining skills, cause it determine students accompanying physical tools to help bureaucracy authenticate geometric thinking through guidance. Due to the students' good conceptual knowledge, they can apply the appropriate concept to a given problem-solving procedure. Students can relate conceptual knowledge and use it to solve the problem in the form of a description of the procedures, increasing students' procedural knowledge. If the conceptual knowledge is associated with the procedural, students can monitor its use and selection to assess the procedural knowledge (Hiebert, 2013). In this study, students who have high scores of conceptual knowledges also have high achievement in procedural knowledge.

The teaching and learning process using the VHG-GSU module learning strategy and VHG-PL module learning strategy has a few notable outcomes. Students increased their conceptual knowledge and procedural knowledge in learning geometry, the teacher and students also enjoyed good interaction. Teachers improved learning environments and expanded the scope of learning by developing instructional materials to deliver teaching information. As a result, students learn more actively by engaging directly with the module and participate in group discussions to achieve the goal of learning. All these motivate and promote the students to be actively involved in learning processes. As conceptual knowledge possessed by the students is one of the indicators that affect students' procedural knowledge (Hiebert, 2013), it has become an important fundamental input among educators to improve conceptual knowledge to improve their ability to solve the algorithm problems that involve symbols and procedures.

\section{Acknowledgments}

I would like to thank my beloved lecturer Prof Aida Suraya and Prof Ahmad Fauzi who always there to guide me to complete this research with correct technique. I also thanks to all the responders who involved in my intervention and submit it. Without them for sure I can't gather information regarding conceptual knowledge and procedural knowledge. In the nut shell I want to thank to everyone who support and give idea and guideline to me during 
conducting this research.

\section{References}

Abdul, H. A. (2013). The development and effectiveness of van Hiele phases of learning geometry with generating conjecture learning strategy in the Geometer's Sketchpad environment. (Unpublished Ph.D. thesis). Universiti Kebangsaan Malaysia, Bangi.

Abdul, H. A., \& Mohini, M. (2008). The use of interactive geometry software (IGS) to develop geometric thinking. Jurnal Teknologi, 49, 93-107. https://doi.org/10.11113/jt.v49.212

Abdullah, N. A. (2019). Mathematics Teachers' Conceptual Knowledge of Algebra: A Literature Review/ Pengetahuan Konseptual Algebra Guru Matematik: Satu Kajian Literatur. Sains Humanika, 12(1). https://doi.org/10.11113/sh.v12n1.1048

Cohen, J. (1988). Statistical power for the behavioural sciences. Hillsdale, NJ: Erlbaum

Fraenkel, J., Wallen, N., \& Hyun, H., (2011). How to Design and Evaluate Research in Education (8th ed.). New York, NY: Mc Graw Hill.

Goker, H., Ozaydin, L., \& Tekedere, H. (2016). The effectiveness and usability of the educational software on concept education for young children with impaired hearing. Eurasia Journal of Mathematics, Science \& Technology Education, 12(1), 109-124. https://doi.org/10.12973/eurasia.2016.1207a

Hiebert, J. (2013). Conceptual and procedural knowledge in mathematics: The case of mathematics. New York, NY: Routledge.

Hutkemri, Z. (2012). Pembangunan dan keberkesanan modul pengajaran Geogebra ke atas pengetahuan konseptual dan prosedural matematik fungsi dan had fungsi. (Unpublished $\mathrm{PhD}$ thesis). Universiti Kebangsaan Malaysia, Bangi.

Hutkemri, Z., \& Effandi, Z. (2012). The effect of using GeoGebra on conceptual and procedural knowledge of high school mathematics students. Asian Social Science, 8(11), 102-106. http://dx.doi.org/10.5539/ass.v8n11p102

Leopold, C. (2008). Virtual and real geometry learning environments. Journal for Geometry and Graphics, 13(1), 1-10. https://www.heldermann-verlag.de/jgg/jgg13/j13h1leop.pdf

Mazlini, A., Azhar, A., Uswatun, K., MohdHairi, Y., Nur Farah, A. B., Nur Ain, A. S., MohdKamarulIrwan, A. R. (2021). Mathematics' Conceptual Knowledge of for Form Four Daily School Students in District of PetalingUtama, Selangor. Turkish Journal of Computer and Mathematics Educatio, 12(3), 675-680.

Mitchelmore, M. C. (2002). The role of abstraction and generalisation in the development of mathematical knowledge. In D. Edge \& Y. B. Har (Eds.), Mathematics education for a knowledge-based era (Proceedings of the Second East Asia Regional Conference on Mathematics Education and the Ninth Southeast Asian Conference on Mathematics Education, 1, 157-167). Singapore: Association of Mathematics Educators. 


\section{Macrothink}

International Journal of Human Resource Studies

ISSN 2162-3058

2021, Vol. 11, No. 4S

National Council of Teachers of Mathematics (NCTM). (2000). Principles and standards for school mathematics : A Guide for Mathematicians. Reston, VA: NCTM.

Noraini, I. (2006). Teaching and learning of mathematics: Making sense and developing cognitive abilities. Kuala Lumpur: Utusan Publications \& Distributors Sdn. Bhd.

Piaget, J. (1978). Success and understanding. Cambridge. MA: Harvard University Press.

Robinson, K. M., \& Dubé, A. K. (2013). Children's additive concepts: Promoting understanding and the role of inhibition. Learning and Individual Differences, 23, 101-107. https://doi.org/10.1016/j.lindif.2012.07.016

Stella, M., Beckage, N. \& Brede, M. (2017). Multiplex lexical networks reveal patterns in early word acquisition in children. Sci. Rep., 7, 46730. https://doi.org/10.1038/srep46730

Sulistyowati, F., Budiyono, B., \& Slamet, I. (2017). Problem solving reasoning and problem based instruction in geometry learning. J. Phys.: Conf. Ser. 895012045. http://doi:10.1088/1742-6596/895/1/012045Usiskin, Z. (1982). van Hiele levels and achievement in secondary school geometry: Cognitive development and achievement in secondary school geometry project. Chicago, IL: University of Chicago Press.

Vitevitch, M. S., \& Castro, N. (2015). Using network science in the language sciences and clinic. International journal of speech-language pathology, 17(1), 13-25. https://doi.org/10.3109/17549507.2014.987819

Vygotsky, L. (1978). Mind in Society: The development of higher psychological processes. Cambridge, MA: Harvard University Press.

Yurniwati, Y., \& Soleh, D. (2019). Geometric conceptual and procedural knowledge of prospective teachers. International Journal Of Education And Pedagogy, 1(2), 108-117. http://myjms.moe.gov.my/index.php/ijeap

\section{Copyright Disclaimer}

Copyright for this article is retained by the author(s), with first publication rights granted to the journal.

This is an open-access article distributed under the terms and conditions of the Creative Commons Attribution license (http://creativecommons.org/licenses/by/4.0/). 